\title{
Knowledge of and misconceptions about the spread and prevention of HIV infection among older urban women attending the Tshwane District Hospital, South Africa
}

\author{
${ }^{a}$ Rauf W, BSc, MBBS, DipPEC(SA), MMed(Fam Med)(UP), AMCEM(SA) a Hitchcock S, MBChB, MPraxMed(UP), MPhil(Pall Med)(UCT) \\ ${ }^{\circ}$ Rauf A, MBBS, FRCS(lre), HDipS(SA), FRCS(Glasg) ' ${ }^{\circ}$ Becker PJ, MSc(Pret), PhD(UNISA) \\ a Department of Family Medicine, Kalafong Hospital and University of Pretoria, Pretoria, South Africa ${ }^{b}$ Department of Orthopaedics, University of Pretoria, Pretoria, South Africa \\ "Division of Clinical Epidemiology, University of Pretoria, Pretoria, South Africa \\ Correspondence to: DrW Rauf, e-mail: nisa.rauf@up.ac.za \\ Keywords: knowledge; HIV; misconceptions; beliefs; older women; transmission; prevention
}

Abstract

SA Fam Pract 2010;52(2):142-148

Background: Statistics around the world show a rapid increase in HIV infection in the older population. Many older women remain sexually active and are therefore exposed to heterosexual transmission of HIV infection. Older women are most likely considered respected opinion leaders within the families and communities and are likely to influence others' attitudes and behaviours. An increase in knowledge through information plays a fundamental role and is a prerequisite for behavioural change that may prevent new HIV infections. The purpose of the current study was to assess the knowledge and misconceptions regarding the spread and prevention of HIV in older women attending the Tshwane District Hospital $(\mathrm{TDH})$ in South Africa.

Methods: A prospective cross-sectional study of 100 women, aged 50 to 80 years, attending the TDH out-patient section during November and December 2006 was done. The levels of knowledge were determined by using a directed questionnaire.

Results: Eight per cent of the participants answered all the questions correctly, showing knowledge gaps in the remaining 92\% (95\% confidence interval: $86.7 \%-97.3 \%$ ). Many participants were unaware of the protective effects of condom use, especially female condoms, and of HIV spread by anal transmission, the sharing of needles and blood transfusion. Three or more misconceptions were present in $48 \%$ of the participants, such as HIV spread by casual contact, the sharing of personal items, air-borne infection, mosquito bites, HIV testing and AIDS prevention or cure by traditional medicines or alternatives. Sixty-two per cent of the older women were found to have adequate knowledge ( $95 \%$ confidence interval: $52 \%-71.5 \%)$, knowing the basic concepts regarding HIV transmission.

Conclusion: There is a significant need for HIV-related preventive health education in older women, not only to decrease potential high-risk behaviours, but also to reduce unnecessary feelings of anxiety and misconceptions. Family physicians, due to their unique role, might be able to use the present study in their practices in order to optimise the planning and structuring of awareness interventions and prevention programmes.

(P) Peer reviewed. (Submitted:2009-05-27, Accepted:2009-09-21). ๑ SAAFP

\section{Introduction}

Sub-Saharan Africa has approximately $70 \%$ of the global total of world's HIV-infected people. ${ }^{1}$ South Africa (SA) has the world's highest number of HIV-infected people, with 11 to $20 \%$ of adults being infected, and 1600 new HIV infections occurring each day. ${ }^{1,2}$ The HIV epidemic has caused a significant increase in morbidity and mortality in SA with long-term bio-psychosocial impacts.

In past decades, HIV infection was considered to be mainly a disease of young people. However, statistics around the world show a rapid increase in HIV infection in the older population. ${ }^{3-6}$ In a Zimbabwean study, $67 \%$ of middleaged and older women attending out-patient clinics were found to be HIV positive. ${ }^{7}$ The HIV Household Survey 2005, conducted in Cape Town, reported a $5.8 \%$ prevalence of HIV in the population of people aged 50 years and older. ${ }^{8}$

The high prevalence of HIV infection among older South Africans calls for the development of targeted interventions for this group. However, there has been little visible commitment to reducing HIV infection in older people. ${ }^{9}$ The assumption that older women are not sexually active and therefore at less risk of contracting HIV infection may account for the lack of AIDS prevention programmes for this population. ${ }^{9}$ However, many older women remain sexually active and are therefore exposed to heterosexual transmission, which is the predominant mode of HIV spread in this group. ${ }^{10,11}$ In such relations, the woman's risk is nine 
times greater than that of her male partner. ${ }^{12}$ Furthermore, older women have a greater susceptibility to contract HIV infection due to the physical changes of menopause, such as vaginal dryness and thinning of the vaginal walls, leading to increased abrasions during unprotected sex. The progression from HIV to AIDS is also faster in the older population. ${ }^{13}$

It is important to regulate exposure to HIV within marriage, where much of the heterosexual transmission occurs. ${ }^{14}$ Most married middle- and older-aged women do not consider themselves at risk of acquiring HIV from their husbands. ${ }^{15,16}$ However, they may be in a relationship with a partner involved in high-risk sexual behaviour without their knowledge. ${ }^{17}$ Over two million HIV-positive people in South Africa seem to be unaware or uncaring of their risk of potentially infecting others. ${ }^{8}$ Studies show that $47 \%$ of men in KwaZulu-Natal and $53 \%$ of Nigerian men have multiple sexual partners. ${ }^{18,19}$ Furthermore, older women are reported to be unable to confront their husbands regarding extramarital affairs. ${ }^{4}$ They do not have equal bargaining power to negotiate safe sex with their married or long-term partner. Gender inequalities and women's lack of choice regarding sexual practices and encounters are further issues that predispose them to HIV infection. ${ }^{4,20}$

Among the other challenges in implementing HIV-prevention interventions are pervasive HIV-related misconceptions such as those regarding HIV spread through casual and non-invasive contact with HIV-positive people.,21-24 These misconceptions have caused fear and AIDSrelated stigmatisation, discrimination, isolation and the abandonment of HIV-positive family members. ${ }^{25}$ They may prevent people from making informed choices regarding HIV testing. ${ }^{22}$ However, few collective efforts have been made to identify and reduce such misconceptions, especially among older women. ${ }^{2}$

Knowledge of the modes of HIV transmission is essential to preventing AIDS. ${ }^{22}$ UNAIDS reported that an increase in knowledge through information is a prerequisite for behavioural change to prevent new HIV infections. ${ }^{26}$ In the USA, a randomised clinical trial evaluated an HIVrisk-reduction intervention on 102 women, based on the information, motivational and behavioural skills model. Follow-up and post-intervention data showed that the enhancement of participants' knowledge regarding HIV transmission strengthened risk-reduction intentions as compared to controls. ${ }^{10}$

While knowledge levels in older women regarding HIV transmission vary among different populations, most of the literature indicates that older women have less knowledge compared to their younger counterparts. ${ }^{3,27-30}$ According to a 2005 survey in South Africa, people aged 50 and older are less aware of national HIV campaigns and programmes and have generally poorer knowledge of key aspects of HIV prevention compared to the younger population. ${ }^{8}$

Older women are most likely considered respected opinion leaders within the families and communities and are likely to influence others' attitudes and behaviours. ${ }^{31}$ In the South African context, a great number of AIDS orphans are being cared for by their grandmothers. Older women are also caregivers of their own adult children and other family members living with AIDS. ${ }^{32}$ Caregivers should have no misconceptions if they are to provide effective care.

The aim of this study was to assess the knowledge of older women regarding HIV spread and prevention and to identify areas of deficient knowledge and misconceptions that might be used in the planning of and assisting with structuring prevention programmes.

\section{Methodology}

\section{Setting and subjects}

A prospective study of 100 women aged 50 to 80 years, attending the Tshwane District Hospital (TDH) out-patient section during November and December 2006 was done. This out-patient section provides primary health care services to the patients living in the central and eastern suburbs of Tshwane.

The sample size was calculated by nQuery version 4 . This sample size was required to obtain a two-sided 95\% confidence interval $(\mathrm{Cl})$ for the proportion of women with adequate knowledge. The sample was collected by systematic sampling on Monday to Friday of each week. The administration clerk of the out-patient section of the hospital compiled a list of all women from 50 to 80 years of age, according to their time of arrival. Every third patient was invited to participate in the study. Older female patients who were willing and able to complete the study questionnaire were included. Patients who were unable to complete the study questionnaire due to mental incompetence or severe physical illness were excluded from this study. Patients who declined to participate were not included and the next scheduled number was selected. Two women refused to participate. They did not give any reason for refusal.

\section{Ethical considerations}

The study was approved by the University of Pretoria's Research and Ethics Committee. All the requirements of this committee were fulfilled, including those with regard to informed consent, anonymity and confidentiality. Patients were interviewed during the waiting periods before seeing a doctor to avoid delaying them due to this research project.

There was no risk or direct benefit involved. However, the correct answers were given to the participants at the end of session. 


\section{Data collection}

Data was collected using an interviewer-administered questionnaire. The validity of the results was increased through the interviewer's being able to clarify questions and answers. The interviews were conducted in separate rooms by a medical doctor supervising the research, and research assistants (nursing students). In order to ensure consistency, the research assistants received training in the application of the questionnaire, interviewing and communication techniques and issues of confidentiality. The language used for the questionnaire was English. The research assistants were capable of speaking the local languages and were able to clarify and translate when language barriers were encountered.

The questionnaire was designed by reviewing previous national and international studies. Most of the questions were taken from a similar American study on older women in order to compare the results. ${ }^{6}$ The questionnaire was finalised by the team of family physicians working in this field. The questionnaire was piloted with 20 women to exclude ambiguous questions. The questionnaire contained 14 closed questions. These questions tested patient knowledge and misconceptions regarding HIV transmission and prevention. The patients were asked about HIV transmission by vaginal and anal sexual intercourse. Other questions included the chance of increased HIV transmission by having multiple sexual partners and protection through the use of male and female condoms. Questions regarding non-sexual transmission were related to touching, kissing (without mixing bodily secretions), sharing needles for injections and receiving non-screened blood transfusions. Questions regarding misconceptions concerned HIV spread by touching and sharing personal items such as utensils, clothes, hair brushes and shoes. In addition, questions on HIV spread by sharing a room with a patient without sexual contact and through mosquito bites, and its transmission by a blood test using standard precautions were asked. The belief that traditional medicines or alternatives such as herbs, garlic and African potatoes can protect from acquiring HIV infection was also examined.

The participants were given the choices 'yes', 'no' and 'do not know'. Knowledge levels were determined by the number of correct answers. Each correct response was marked as one. Incorrect or do-not-know responses were marked as zero. A total of ten or more correct responses out of fourteen was categorised as adequate knowledge. Knowledge levels were calculated as percentages of correct responses out of the total of 14 questions. Validity and reliability checks were done.

\section{Data analysis}

Univariate statistical analysis was done. The Intercooled Stata 8.1 (Intercooled for Windows; STATA Corp, College Station, Tex; 2003) statistical package was used.

The total score of each participant as well as the responses to the individual questions were summarised using frequencies, percentages and graphs. The total score over the 14 knowledge questions was used to dichotomise the subjects as to whether they had adequate or inadequate knowledge. The proportion of women with adequate knowledge was estimated along with a $95 \% \mathrm{Cl}$. Fisher's exact testing was used for the data analysis to determine any significant knowledge differences for different demographic groups. Testing was at the 0.05 level of significance.

\section{Results}

Of the 100 patients studied, $57 \%$ were 50 to 59 years old, compared to $43 \%$ that were 60 to 80 years old. The majority of the patients were black (59\%); the remainder being white $(36 \%)$ and of other racial groups (5\%).

Sixty-two per cent of the older women were found to have adequate knowledge (95\% Cl: 52\%-71.5\%). Eight per cent of the participants answered all the questions correctly, showing knowledge gaps in the remaining 92\% $(95 \% \mathrm{Cl}$ : $86.7 \%-97.3 \%)$. Various knowledge levels of the participants, as calculated by the correct responses out of the total of 14 questions, are shown in Table 1. The minimum knowledge level was $21.4 \%$ (three correct responses), found in one participant. The knowledge levels of the majority of the participants were between $64.28 \%$ (nine correct responses) and $92.85 \%$ (thirteen correct responses), as shown in Table 1.

Data were analysed to determine whether the demographic variables, such as prior education level, age group and race, influenced the knowledge level, as shown in Table II.

Women with higher education were found to have significantly more knowledge compared to their counterparts with no education or only primary education ( $p<0.001$; $80.4 \%$ vs $42.9 \%$; $95 \% \mathrm{Cl}: 19.9 \%-55.2 \%$ ). A comparison of the knowledge levels of women in the 50 to 60 -years age group with the 61 to 80 -year age group showed no statistically significant difference ( $p=0.128 ; 68.4 \%$ vs $53.5 \%$; $95 \% \mathrm{Cl}$ : $-4.2 \%-31.4 \%)$. There was no statistical difference in the overall knowledge among the different races $(p=0.081$; $72.2 \%$ vs $54.2 \%$; $95 \% \mathrm{Cl}:-1.4 \%-37.4 \%$ ).

Table l: Knowledge levels of older female participants

\begin{tabular}{|l|c|c|c|c|c|c|c|c|c|c|c|c|}
\hline Total $\mathbf{n}=100$ & 1 & 4 & 6 & 2 & 5 & 6 & 14 & 16 & 10 & 15 & 13 & 8 \\
\hline Knowledge level (percentage) & 21.42 & 28.57 & 35.71 & 42.85 & 50 & 57.14 & 64.28 & 71.42 & 78.57 & 85.71 & 92.85 & 100 \\
\hline
\end{tabular}


Table II: The relationship between HIV-related knowledge and socio-demographic factors

\begin{tabular}{l|c|l|}
$\begin{array}{l}\text { Demographic } \\
\text { variables }\end{array}$ & $\begin{array}{c}\text { Total } \\
\mathbf{n = 1 0 0}\end{array}$ & $\mathbf{P}$ values, $\mathbf{C l}$ \\
\hline $\begin{array}{l}\text { Age in years } \\
50-60\end{array}$ & 57 & $\mathrm{p}=0.128 ; 68.4 \%$ vs $53.5 \%$; \\
$61-80$ & 43 & $95 \% \mathrm{Cl}:-4.2 \%-31.4 \%$ \\
\hline Race & & \\
Black & 59 & $\mathrm{p}=0.081 ; 72.2 \%$ vs $54.2 \% ;$ \\
White & 36 & $95 \% \mathrm{Cl}:-1.4 \%-37.4 \%$ \\
Coloured & 4 & \\
Indian & 1 & \\
\hline Education & & \\
None & 15 & $\mathrm{p}<0.001 ; 80.4 \%$ vs $42.9 \% ;$ \\
Primary & 34 & $95 \% \mathrm{Cl}: 19.9-55.2 \%$ \\
High & 41 & \\
Tertiary & 10 &
\end{tabular}

Incorrect responses were examined to highlight areas with knowledge gaps. Figure 1 shows the total number of incorrect responses regarding sexual and non-sexual interactions.

The main area of deficient knowledge regarding sexual transmission was the use of female condoms $(37 \%$ incorrect responses; $95 \% \mathrm{Cl}: 27.5 \%-46.5 \%)$. A significant number of participants did not know about the anal mode of HIV transmission and protection from it by using male condoms. Regarding non-sexual transmission, the major misunderstanding was about HIV spread by kissing without the mixing of bodily secretions (33\% incorrect responses; $95 \%$ Cl: $23.8 \%-42.2 \%)$.

Figure 2 depicts the number of participants that had misconceptions.
Figure 1: Incorrect responses regarding HIV transmission

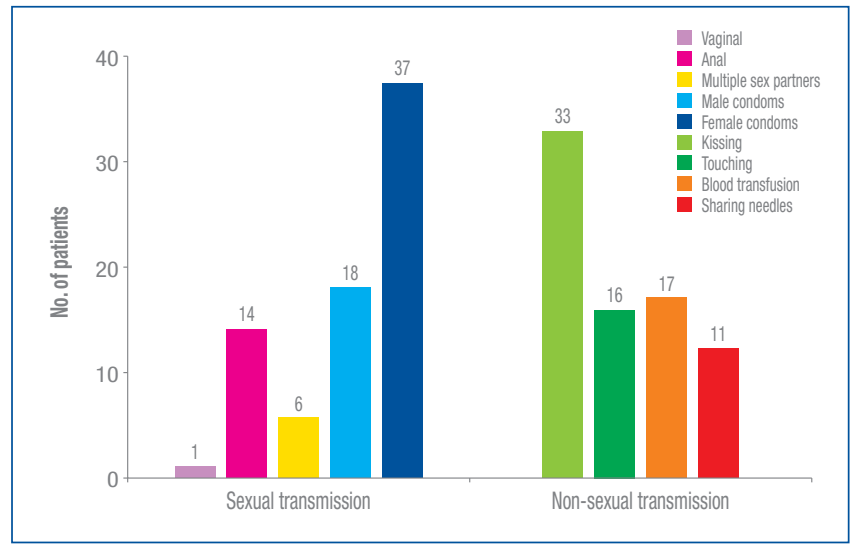

Figure 2: Misconceptions regarding HIV transmission

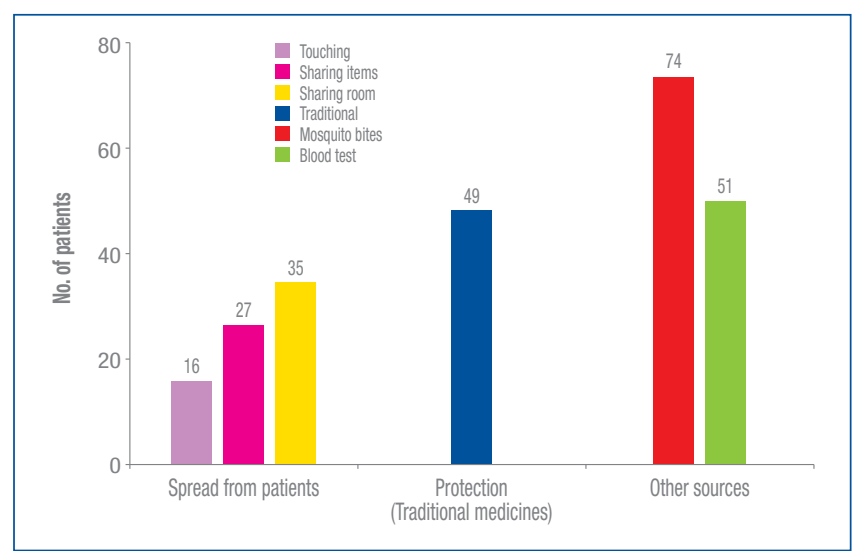

Thirty-five per cent of the participants $(95 \% \mathrm{Cl}: 27.5 \%-$ 44.3\%) thought that HIV infection could spread by sharing a room with an HIV-positive patient without any kind of sexual contact. Twenty-seven per cent (95\% Cl: 18.3\%-35.7\%) had the misconception that HIV could be spread by sharing

Table III: The relationship between HIV-related misconceptions and socio-demographic factors

\begin{tabular}{|c|c|c|c|c|c|}
\hline & $\begin{array}{c}\text { No } \\
\text { misconceptions }\end{array}$ & $\begin{array}{c}1-2 \\
\text { misconceptions }\end{array}$ & $\begin{array}{c}3 \text { or more } \\
\text { misconceptions }\end{array}$ & $\begin{array}{c}\text { Total } \\
n=100\end{array}$ & $\begin{array}{c}\text { P values } \\
\text { (Fisher's exact test) }\end{array}$ \\
\hline $\begin{array}{l}\text { Age (years) } \\
50-60 \\
61-80\end{array}$ & $\begin{array}{l}5 \\
9\end{array}$ & $\begin{array}{l}22 \\
16\end{array}$ & $\begin{array}{l}30 \\
18\end{array}$ & $\begin{array}{l}57 \\
43\end{array}$ & 0.229 \\
\hline $\begin{array}{l}\text { Race } \\
\text { Black } \\
\text { White } \\
\text { Others }\end{array}$ & $\begin{array}{l}5 \\
9 \\
0\end{array}$ & $\begin{array}{c}19 \\
16 \\
3\end{array}$ & $\begin{array}{c}35 \\
11 \\
2\end{array}$ & $\begin{array}{c}59 \\
36 \\
5\end{array}$ & 0.010 \\
\hline $\begin{array}{l}\text { Education } \\
\text { None } \\
\text { Primary } \\
\text { High } \\
\text { Tertiary }\end{array}$ & $\begin{array}{c}0 \\
1 \\
10 \\
3\end{array}$ & $\begin{array}{c}3 \\
13 \\
20 \\
2\end{array}$ & $\begin{array}{c}12 \\
20 \\
11 \\
5\end{array}$ & $\begin{array}{l}15 \\
34 \\
41 \\
10\end{array}$ & 0.001 \\
\hline $\begin{array}{l}\text { Self-rating* } \\
\text { No* } \\
\text { Minimum* } \\
\text { Maximum* }\end{array}$ & $\begin{array}{l}0 \\
5 \\
9\end{array}$ & $\begin{array}{c}3 \\
28 \\
7\end{array}$ & $\begin{array}{c}9 \\
36 \\
3\end{array}$ & $\begin{array}{l}12 \\
69 \\
19\end{array}$ & $<0.001$ \\
\hline
\end{tabular}


personal items such as utensils, clothes, hair brushes and shoes. Half of the participants (49\%; 95\% Cl: $48.8 \%-$ $61.1 \%)$ thought that HIV transmission could be prevented by the use of traditional medicines or alternatives. The majority (74\%; $95 \% \mathrm{Cl}: 27.5 \%-46.5 \%)$ of the participants had a fear that they could acquire HIV if a mosquito bit them after biting an HIV-positive patient. More than half of the participants were not in favour of an HIV-screening test due to the misconception that they might acquire the infection by this test.

The effect of socio-demographic factors on HIV-related misconceptions is shown in the Table III. This comparison is based on six out of the total of fourteen questions regarding misconceptions, as highlighted in Figure 2.

Eighty-six per cent of the participants had at least one misconception; however, $48 \%$ had as many as three or more misconceptions. As shown in Table II, there was a significant difference in HIV-related misconceptions in different races, previous education levels and in the groups according to their self-rating about HIV knowledge.

\section{Discussion}

The knowledge and attitudes of older people regarding HIV transmission are important not only to protect themselves but also to influence the younger population, being opinion leaders in families. ${ }^{31}$ It was expected that, due to the high prevalence of HIV in Africa, South African older women would be more knowledgeable of HIV transmission than would women in American studies. ${ }^{1}$ However, it was found that knowledge levels in this study were lower than those found in several American studies. In an American study on women aged 50 years and older, $59 \%$ of the participants answered $90 \%$ of the questions correctly compared to only $21 \%$ of the participants who achieved $90 \%$ or more correct responses in this study. ${ }^{3}$ In another study on older African Americans (> 55 years), $80 \%$ of the participants were found to have adequate knowledge compared to $62 \%$ in the present study. ${ }^{9}$ However, in yet another American study, urban older women (aged 50 and older) demonstrated very little knowledge of HIV. The mean knowledge score found was 3.7 out of a possible nine correct answers. ${ }^{6}$ No similar African study was found in the literature to compare the knowledge levels of older female participants with the present study.

The poorer knowledge levels of South African participants may be related to the lower education levels of many of the participants. Higher education was associated with better knowledge of HIV. ${ }^{10}$ Significant differences in knowledge levels and misconceptions were observed among groups with differences in previous formal education, confirming the findings of other South African, Nigerian and American studies. ${ }^{2,6,33}$ A study in Botswana showed that people with no formal education were 10 times more likely to harbour misconceptions regarding HIV transmission and prevention than those who had a tertiary education. ${ }^{22}$ The black participants in the present study had significantly more misconceptions compared to their white counterparts. This may again be related to lower education; since black older women did not have equal opportunities to education as did their white counterparts.

It is likely that there are several other factors influencing the knowledge levels in the study, such as social circles, media, newspaper exposure, life style and affiliation with libraries. ${ }^{6}$ In more open societies people are able to discuss such issues more frequently, which leads to the improvement of knowledge levels, as compared to the situation in more conservative societies.

In SA, long-term marital relationships with husbands having multiple sexual partners and HIV sero-discordance in marriages are great challenges. ${ }^{14}$ There is a need for sound knowledge in these women, as less awareness is associated with a decreased risk perception. ${ }^{16}$ Many participants in this study were unaware of some of the major modes of HIV transmission, such as anal sex.

The literature shows that older women, over the age of 50 , do not have sufficient information on the effectiveness of condoms to protect against HIV transmission, as also confirmed by the present study. ${ }^{6,7,9,27}$ A great number of participants in the present study were unaware of female condoms. There is a strong correlation between poor HIV knowledge and decreased condom use. ${ }^{7,16}$ Condom use increases with the awareness of its effectiveness against HIV. $^{34}$ Gender inequalities and women's lack of choice regarding sexual practices and encounters are other issues that predispose them to $\mathrm{HIV}^{4,20}$ Female condoms were recognised as an alternative device that is helpful in situations of male domination. ${ }^{20}$ However, some women did not consider them enjoyable, or mentioned that their partners rejected it. ${ }^{34,35}$ The majority of the women found the device easy to use..$^{35}$ Eighty-five per cent of women in the USA felt more in control of disease protection by using female condoms rather than by having their partners use male condoms. ${ }^{36}$

The misconceptions found in the present study are similar to those of other international studies. One third of the participants believed that HIV could be transmitted by kissing without any contact with bodily secretions, confirming the finding of an American study on older women. ${ }^{6}$ In an extensive study across four countries, namely Ethiopia, Zambia, Vietnam and Tanzania, there was a common fear that HIV could be transmitted through ordinary interactions. Examples were shaking hands, kissing on the cheek, sitting next to an HIV-positive patient, eating food prepared by an HIV-positive person, breathing infected air and using 
objects, such as clothing, bedding or eating utensils, that have been touched by HIV-positive patients. ${ }^{21}$ In Thailand most of the older people overstated the risk of contracting HIV by casual contact through, for example, sharing a meal, eating utensils or a room with an HIV-positive patient. ${ }^{31}$ The present study confirmed the presence of the abovementioned misconceptions among the older females at TDH. One-quarter of the participants in this study believed that HIV could be spread by sharing personal items such as utensils, clothes, hair brushes and shoes. Eighteen per cent of the participants in a South African National Household Survey 2002 (including all age groups), compared with $35 \%$ of older female participants in the present study, were unwilling to sleep in the same room with someone with AIDS. ${ }^{37}$ A Cape Town study confirmed that participants with similar misconceptions showed repulsive attitudes towards AIDS patients. ${ }^{2}$ Such misconceptions have a severely negative impact on the lives of HIV-infected people, such as loss of marriage partner or job, discrimination and avoidance by family members, friends and the society as a whole. ${ }^{21}$ Older South African women often have the role of caretaker of their grandchildren, whose parents might have died due to AIDS. The presence of such misconceptions in this population group therefore presents a social dilemma. ${ }^{32}$

The fear of contracting HIV through highly unlikely routes may be due to a lack of specific, in-depth information on HIV transmission. Research illustrates that people try to apply the little information they receive to the reality of their daily lives, leading to incorrect conclusions about the risk posed by casual transmission. Because they know that TB is airborne, that diarrhoea is contracted through infected food or water and malaria through mosquitoes, people often reason that HIV might also be transmitted through these routes as well. ${ }^{21}$ In the current study, $74 \%$ of the participant as compared to $35.3 \%$ of women in a Nigerian study thought that the HIV could be transmitted by mosquito bites. ${ }^{33}$ People with this belief are more likely to avoid AIDS patients with the fear that the same mosquito may bite them after biting such patient. In Vietnam, women aged 50 years and older believed that ideally their government should isolate HIV-positive patients on an island to live and work together in order to save the rest of population. ${ }^{21}$

The fear of isolation and stigmatisation prevents people from getting tested for HIV. ${ }^{21}$ In addition, more than half of the participants in the present study thought that they may acquire HIV infection during the process of testing for HIV.

Nearly half of the participants in the present study as compared to one-third of older participants in Thailand thought that traditional medicines or alternatives could protect them from acquiring HIV. ${ }^{31}$ It is possible that the people with such misconceptions may continue to be involved in risky behaviours because of their inadequate knowledge of HIV spread. There is a need to educate older women about HIV, both for their own protection and to alleviate anxiety regarding unnecessary misconceptions, in order to better support their roles as caregivers in society.

We did not find any definitive South African policy regarding the increase of HIV-related knowledge that specifically targets older women. Even a recent American study reported a gap in HIV research and a lack of national policies relating to HIV prevention in older African American women living in the USA. ${ }^{38}$

\section{Limitations and biases}

The design of the current study was cross-sectional; therefore, it did not permit predictive or causal interpretation of the findings. In addition, this study was limited to the urban population. The results of the study could, therefore, not be extrapolated to the general population. Eighty-five per cent of the participants in the present study had some formal school education. There might be a huge decrease in education level if a similar study is conducted in a rural community, meaning that there would be an even greater need for health education in those communities. Participant bias could not be excluded due to the sensitive nature of the questionnaire. However, reporter bias was reduced by prior training of the research assistants regarding intervieweradministered questionnaires.

\section{Conclusion and recommendations}

It is evident from this study that older women could benefit from further information on HIV transmission and prevention.

Attention should therefore be given to improving HIV-related information especially among less-educated black older women. The focus area of education should be the use of condoms and the particular benefits of female condoms. Special attention could be given to misconceptions regarding HIV transmission through casual contact or HIV testing. It is vital to dispel the myths surrounding traditional medicines or alternatives and protection from HIV infection.

Target patients could be educated in small interactive groups during waiting periods in the clinics. Retired health professionals or other educated and motivated jobless people could serve this purpose after formal training, at minimal cost. Public media education campaigns targeting the older population may improve HIV-related awareness in this group. ${ }^{38}$

Family physicians could play a major role in patient education regarding HIV health promotion, since the unique nature of the relationship between family physicians and their patients places them in the best position to understand their patients' contexts. ${ }^{39}$ 
Family physicians are frequently involved in clinics, district hospitals and health systems in South Africa. They could participate in developing an organised network of older women and health care providers to improve HIV knowledge in older women.

The lack of effective, targeted HIV education and prevention strategies means that HIV infection among older women will continue. There is a need to draft policies at local and national level targeting older women. The findings of this study may be of benefit to the design of awareness interventions required to improve knowledge regarding the spread and prevention of and misconceptions about HIV.

\section{Acknowledgement}

The guidance and support given by Professor Julia Blitz is highly appreciated. We acknowledge the help

provided by Mrs Myleen Oosthuizen in literature search.

\section{References}

1. Discovery Institute (SA). HIV/AIDS management course for health care professionals. South Africa: Discovery Institute; 2004.

2. Kalichman SC, Simbayi L. Traditional beliefs about the cause of AIDS and AIDS-related stigma in South Africa. AIDS Care 2004 Jul;16(5):572-80.

3. Yates ME, Stellato RK, Johannes CB, Avis NE. The importance of AIDSrelated knowledge for mid-life and older women. AIDS Educ Prev 1999 Jun;11(3):224-31

4. McCalman CL. Barriers and motivators for low-income Brazilian women in metropolitan Belo Horizonte: Insights for AIDS prevention. Health Care Women Int 2003 Jul;24(6):565-85.

5. Schable B, Chu SY, Diaz T. Characteristics of women 50 years of age or older with heterosexually- acquired AIDS. Am J Public Health 1996 Nov;86(11):1616-8.

6. Henderson SJ, Bernstein LB, George DM, Doyle JP, Paranjape AS, CorbieSmith G. Older women and HIV: How much do they know and where are they getting their information? J Am Geriatr Soc. 2004 Sep;52(9):1549-53.

7. Mbizvo EM, Msuya SE, Hussain A, Chirenje MZ, Stray-Pedersen B. HIV prevalence in Zimbabwean women: 54-67\% knowledge and perceived risk. Int J STD AIDS 2003 Mar;14(3):202-7.

8. South African national HIV prevalence, HIV incidence, behaviour and communication survey. Cape Town: Human Sciences Research Council; 2005. Available from http://0-www.hst.org.za.innopac.up.ac.za/indicators/ HIV_AIDS/HIV_HouseholdSurvey2005.pdf (Accessed Nov 2008).

9. Rodgers-Farmer AY. HIV risk factors, HIV antibody testing, and AIDS knowledge among African Americans age 55 years and older. Soc Work Health Care 1999;29(3):1-17.

10. Carey MP, Braaten LS, Maisto SA, et al. Using information, motivational enhancement, and skills training to reduce the risk of HIV infection for lowincome urban women: A second randomized clinical trial. Health Psychol 2000 Jan;19(1):3-11.

11. Theall KP, Elifson KW, Strk CE, Klein H. Perceived susceptibility to HIV among women: Differences according to age. Research on Aging 2003;25(4):405-432.

12. Padian NS, Shiboski SC, Glass SO, Vittinghoff E. Heterosexual transmission of human immunodeficiency virus (HIV) in Northern California: Results from a ten-year study. Am J Epidemiol 1997 Aug 15;146(4):350-7.

13. Hinkle K. HIV seropositivity in the elderly. J Gerontol Nurs 1991;17:12-17.

14. Reniers G. Marital strategies for regulating exposure to HIV. Demography 2008; 45(2):417-38.

15. Peltzer K. Factors affecting behaviours that address HIV risk among black and white South Africans. Curationis 2002 Aug;25(3):19-22.

16. Tang CS, Wong CY, Lee AM. Gender-related psychosocial and cultura factors associated with condom use among Chinese married women. AIDS Educ Prev 2001 Aug;13(4):329-42.

17. Maharaj P, Cleland J. Risk perception and condom use among married or cohabiting couples in KwaZulu-Natal, South Africa. Int Fam Plann Perspect 2005 Mar;31(1):24-9.

18. Fredlund VG, Hartung TK, Nash J, Ngubane N. AIDS awareness and sexual behaviour in a high HIV prevalence area in rural northern KwaZulu-Natal, South Africa. Inter J of STD \& AIDS 2002 Dec; 13(12):829-32.

19. Adebajo SB, Odujinrin MT. Social characteristics, HIV/AIDS knowledge preventive practices and risk factors elicitation among prisoners in Lagos, Nigeria. West Afr Med J 2001 Jul;20(3):191-8.

20. Hart GJ, Pool R, Green G, Harrison S, Nyanzi S, Whitworth JA. Women's attitudes to condoms and female-controlled means of protection against HIV and STDs in south-western Uganda. AIDS Care 1999 Dec;11(6):687-98.

21. Ogden J, Nyblade L. Common at its core: HIV-related stigma across context. Washington: International Center for Research on Women; 2005.

22. Letamo G. Misconceptions about HIV prevention and transmission in Botswana. AJAR 2007;6(2):1938.

23. Parsons SK, Cruise PL, Davenport WM, Jones V. Religious beliefs, practices and treatment adherence among individuals with HIV in the Southern United States. AIDS Patient Care STDS. 2006 Feb;20(2):97-111.

24. Abdelmajed A, Al-Serouri AW, Aldobaibi A, Oshish $H$, Takioldin $M$ Knowledge, attitudes and beliefs about HIV/AIDS in Sana'a, Yemen. Eastern Mediterranean Health J 2002 Nov; 8(6):706-15.

25. Ross MW, Essien EJ, Torres I. Conspiracy beliefs about the origin of HIV/ AIDS in four racial/ethnic groups. J Acquir Immune Defic Syndr 2006 Mar;41(3):342-4.

26. UNAIDS. National AIDS programmes: A guide to monitoring and evaluation. Geneva: United Nations; 2000.

27. Peltzer K, Seoka P, Raphala S. Characteristics of female sex workers and their HIV/AIDS/STI knowledge, attitudes and behaviour in semi-urban areas in South Africa. Curationis 2004 Mar;27(1):4-11.

28. Pinkerton SD, Dyatlov RV, DiFranceisco W, et al. HIV/AIDS knowledge and attitudes of STD clinic attendees in St. Petersburg, Russia. Aids Behav 2003 Sep;7(3):221-8

29. Al-Owaish R, Moussa MA, Anwar S, Al-Shoumer H, Sharma P. Knowledge, attitudes, beliefs, and practices about HIV/AIDS in Kuwait. AIDS Educ Prev 1999 Apr;11(2):163-73

30. Mabunda G. HIV knowledge and practices among rural South Africans. J Nurs Scholarsh 2004;36(4):300-4

31. Im-em W, Vanlandingham M, Knodel J, Saengtienchai C. HIV/AIDS-related knowledge and attitudes: A comparison of older persons and young adults in Thailand. AIDS Educ Prev 2002 Jun;14(3):246-62.

32. Hamra M, Ross MW, Karuri K, Orrs M, D'Agostino A. The relationship between expressed HIV/AIDS-related stigma and beliefs and knowledge about care and support of people living with AIDS in families caring for HIVinfected children in Kenya. AIDS Care 2005 Oct;17(7):911-22.

33. Kayode CM, Adeyemo AA, Omotade OO. Beliefs and perceptions about HIV infection and AIDS among mothers of infants in Ibadan, Nigeria. West African Journal of Medicine 2002 Jan-Mar;21(1):43-7

34. Lindberg CE. Knowledge, self-efficacy, coping, and condom use among urban women. J Assoc Nurses AIDS Care 2000 Sep-Oct;11(5):80-90.

35. Beksinska ME, Rees VH, McIntyre JA, Wilkinson D. Acceptability of the female condom in different groups of women in South Africa: A multicentred study to inform the national female condom introductory strategy. SAMJ 2001 Aug;91(8):672-8.

36. Vieira EM, Machado AA, Duarte G, De Souza RH, Rodrigues AL Jr. The use of the female condom by women in Brazil participating in HIV prevention education sessions. Rev Panam Salud Publica 2004 Jun;15(6):373-9.

37. Shisana O, Simbayi L. Nelson Mandela / HSRC Study of HIV/AIDS: South African National HIV Prevalence, Behavioral Risks and Mass Media Household Survey 2002. Human Sciences Research Council; 2002.

38. Jacobs RJ, Kane MN. Theory-based policy development for HIV prevention in racial/ethnic minority mid-life and older women. Journal of Women \& Aging 2009;21(1):19-32.

39. McWhinney IR. A text book of family medicine. New York: Oxford University Press; 1997. 